\title{
Procalcitonin for Antibiotic Treatment in Intensive Care Unit Patients
}

\author{
Nathalie Layios • Bernard Lambermont
}

Published online: 10 August 2013

(C) Springer Science+Business Media New York 2013

\begin{abstract}
Procalcitonin (PCT), a 116-aminoacids prohormone, has been substantially studied over the last 2 decades in the field of sepsis. Disappointingly low sensitivity values led to the abandonment of the concept of it as a diagnostic tool and then to its being considered more as a prognostic marker with a good correlation with severe infection. Later on, growing concerns about multidrug-resistant bacteria in the ICU environment and about the cost and side effects of antibiotics suggested that PCT might prove to be a valuable asset in stewardship programs. Numerous but hardly comparable randomized controlled trials assessing either initiation or deescalation in ICU patients have been published. Stewardship encompassing PCT should focus on the latter, because of the high negative predictive value of this biomarker. However, there still would be safety concerns if a systematic implementation of PCT were to be considered in daily stewardship programs in the ICU, especially in extrathoracic sepsis.
\end{abstract}

Keywords Procalcitonin $\cdot$ Diagnosis $\cdot$ Prognosis $\cdot$ Initiation · De-escalation · Antibiotic Stewardship · Intensive care unit . Cost-effectiveness $\cdot$ Safety

\section{Introduction}

Since its first description in children and burned patients 2 decades ago [1], procalcitonin (PCT) has traveled a long way from diagnosis of infectious chronic obstructive pulmonary

\footnotetext{
N. Layios $(\bowtie)$

Department of General Intensive Care, University Hospital Centre of Liege, Domaine universitaire du Sart-Tilman, 4000 Liege, Belgium e-mail: Nathalie.Layios@chu.ulg.ac.be

B. Lambermont

Department of Intensive Care Medicine, University Hospital Centre of Liege, Liege, Belgium

e-mail: B.Lambermont@chu.ulg.ac.be
}

disease (COPD) exacerbation in the emergency department to its current concept as a possible tool for antibiotic stewardship in our busier intensive care units (ICUs) with worsening ecological environments [2, 3] (Fig. 1). Indeed, it was first thought to be helpful in the discrimination between severe infection and nonspecific hyperinflammatory states [4•]. Intensive care physicians are daily challenged with the risk of initiating useless and potentially toxic (for the patient and the environment) treatments in the absence of specific clinical signs and of a gold-standard biomarker in the field of sepsis. PCT was historically studied in various settings and clinical conditions, including emergency departments, neonatal sepsis, and ICU patients $[5,6]$. However, unacceptably low sensitivity values in the setting of critically ill patients, ranging from $67 \%$ to $80 \%$ depending on the chosen cutoff $[7,8,9 \bullet, 10 \bullet]$, led to its being considered rather as a prognostic tool in terms of severity of illness and outcome. In that sense, PCT met the fate of other acute phase reactants that did not show satisfactory specificity. PCT is notoriously raised, in the absence of infection, in pancreatitis, ischemic bowel disease, cardiopulmonary bypass, and metastatic disease [11] and with the intake of some drugs (monoclonal antibodies, antithymocyte globulin, etc.) [12••, 13]. PCT does not rise incases of local bacterial, viral, parasitic, or fungal infection. Between 2006 and 2008, numerous studies involving very different types of patients (medical vs. surgical, immunocompetent vs. immunocompromised) and indications (severe community-acquired pneumonia, sepsis) $[14,15]$ were undertaken. Some studies focused strictly on prognostic significance, whereas others combined the diagnostic and prognostic abilities of the test. Interestingly, PCT was combined with others biomarkers (CRP, sTREM-1, SUPAR, TNF-alpha, IL6, IL-8), clinical scoring systems (SAPSII), and biological markers of sepsis such as lactate [16-18]. The results were better in the multimodal approach, as opposed to the use of PCT alone, for determination of outcome (AUC 0.72-0.88). It is now commonly admitted that higher values $(1.5$-over $5 \mu \mathrm{g} / \mathrm{l})$ in high-risk patients are correlated with bacterial load and 
Fig. 1 Number of procalcitonin publications including adult ICU trials

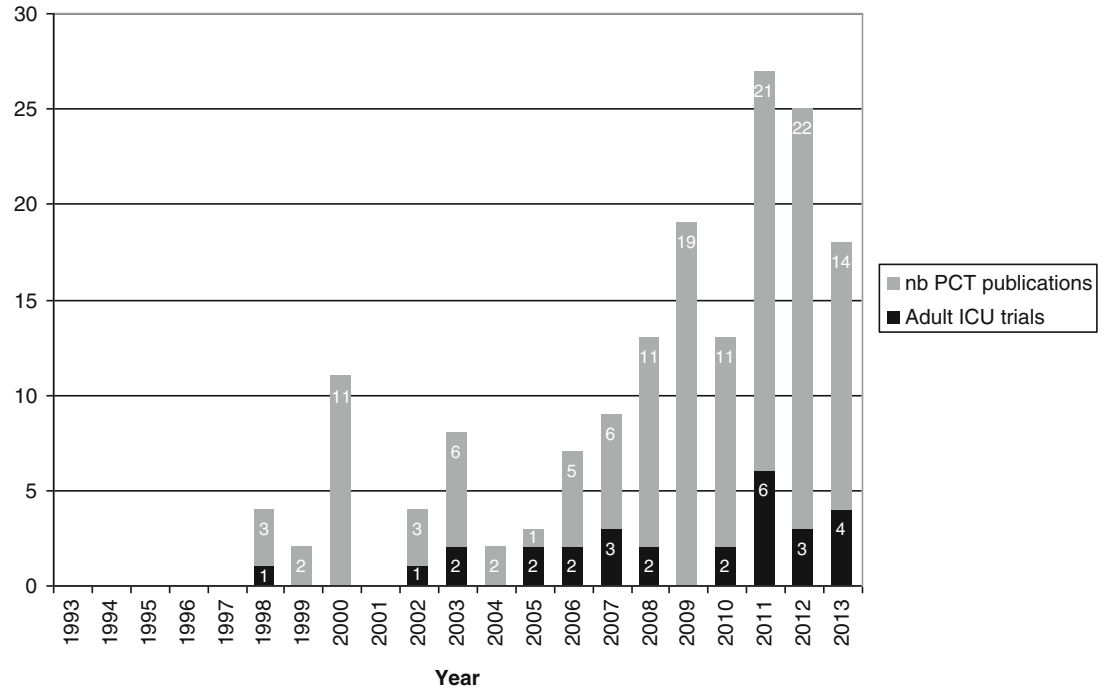

bacteremia [19], severity of organ failure [20, 21], and, in some studies, mortality $[6,22]$.

\section{Core Text}

After an initial encouraging report on the usefulness of PCT for safe reduction of antibiotic therapy in lower respiratory tract infections (RTIs) in 2004 [23, 24], it was not until 2008 that the concept of PCT as a possible antibiotic stewardship tool emerged in clinical studies involving ICU patients [25••] (Table 1). The growing pressure of multidrug-resistant bacteria in the ICU environment, combined with considerations regarding cost and limitation of drug toxicity and interactions $[26,27]$, offered the perfect opportunity for a new appraisal of this biomarker, which had somehow failed to fulfill its promises. It is considered to be useful because of favorable kinetics [28] and a high negative predictive value [17, 29-31].

Antibiotic stewardship encompassing PCT can be regarded as a lack of initiation of antibiotics in the absence of bacterial infection, thus calling into question the sensitivity of the biomarker, versus rapid stopping of them, in cases of a decrease of PCT, on the basis of a daily check, either because clinical cure is achieved or because infection has been safely ruled out.

Now, the first strategy encounters two hurdles. First, it obviously does not fit into clinical practice dealing with seriously ill patients, since protocol-overruling reports range from $20 \%$ to $65 \%$ [30, 32•, 33, 34]. In the Layios study, in 43/80 patients (belonging to the PCT arm, which comprised 258 patients) who had a PCT $<0.25 \mu \mathrm{g} / \mathrm{l}$, the diagnosis was overruled by the treating physician, and they received antibiotics. Of note, $69.8 \%$ of these treatments $(30 / 43)$ were a posteriori confirmed by the infectious diseases specialist to have been appropriately initiated. Second, poor diagnostic sensitivity was once again confirmed recently (AUC 0.69), and two recent studies showed that the strategy is a failure in an escalating or initiation process $[10 \bullet, 30]$.

The second strategy, however, is supported by the physiological decline within $48 \mathrm{~h}$ in noninfected patients $[35,36]$ and has recently been shown to be cost effective, thanks to a 2-day decrease in antibiotic consumption, although not altogether convincingly safe $[32 \cdot, 37]$. The same degree of concern about a possible excess of mortality had been raised in the PRORATA study [33], and the debate is ongoing. Prior to 2010, five randomized controlled trials (RCTs) evaluating deescalation in critically ill patients had shown reduction in antibiotic consumption, without excess of morbidity or mortality [38]. Interestingly, the same authors put into perspective the fact that in nondocumented sepsis, the optimal duration of antibacterial therapy is not known. Several other studies have been published since then, reporting the same proportion of safe antibiotic-free days (2-4 days) [31, 39•, 40], but only two focused merely on severe extra-thoracic sepsis. The ESICM meta-analysis reviewed seven RCTs in critically ill patients and confirmed the safety of shortening antibiotic administration by just over 3 days, in terms of a similar rate of superinfections and recurrence of infection in the PCT-guided arm. A consistent reduction of antibiotic therapy was also reported in the review published by Schuetz et al. [41••], mainly owing to shorter courses of antibiotic therapy (and not withholding of initiation) among moderate- and high-acuity care patients. The Schuetz study mixed lower RTIs and severe sepsis and septic shock without further definition. The proposed PCT cutoff values in the deescalating strategy in the ICU were roughly the same throughout all the recently published trials and metaanalyses, meaning a drop of $80 \%-90 \%$ from the peak value or a return to a level less than $0.25-1 \mu \mathrm{g} / \mathrm{l}$ in patients showing clinical signs of recovery. Mortality has not been significantly affected by that strategy in any of the trials published so far. Importantly, PCT was extensively studied in the setting of 


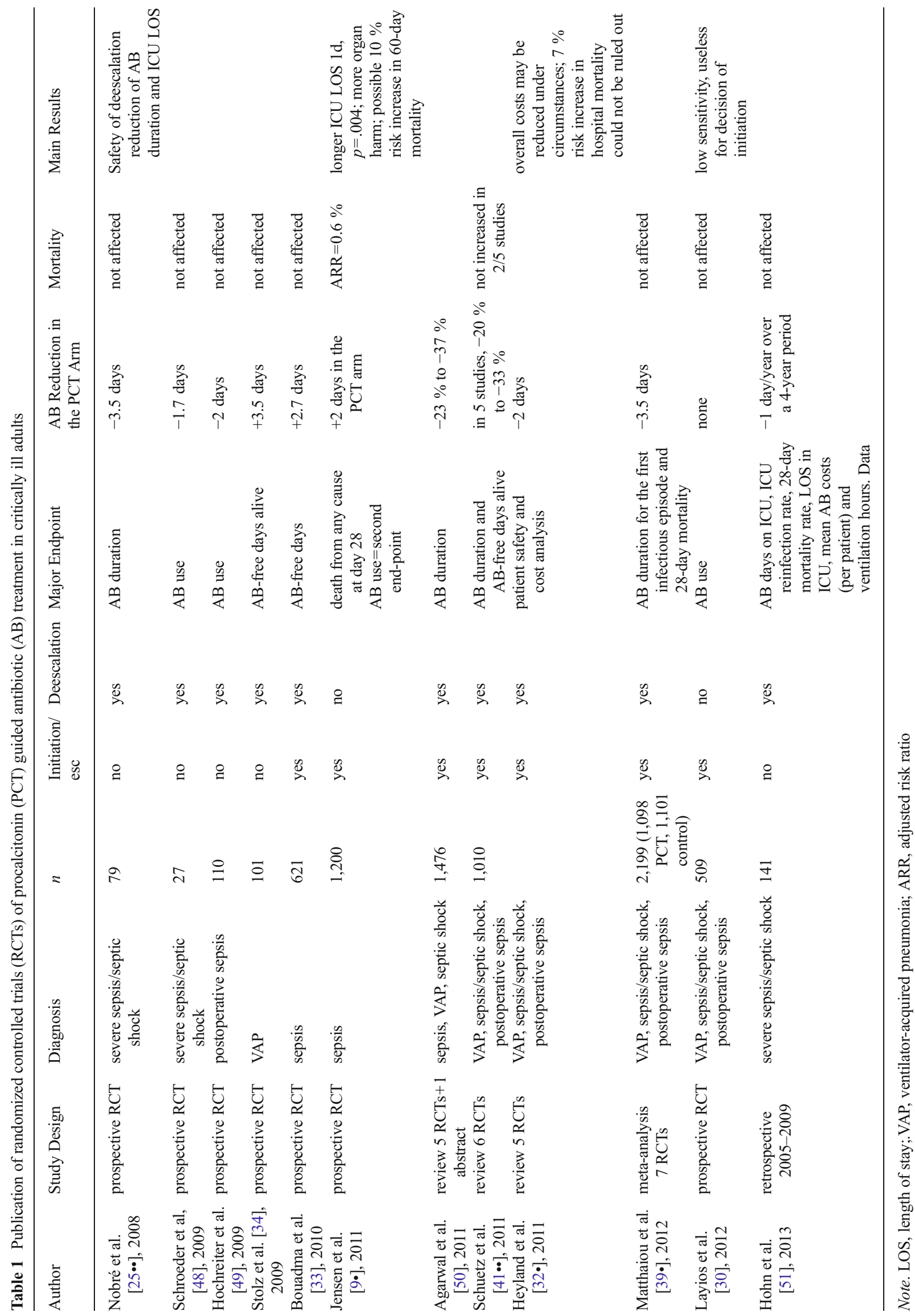


lower RTIs namely, ventilator-acquired pneumonia (VAP) in immunocompetent adults - while severe sepsis (i.e., a syndrome defined as the host's systemic inflammatory response syndrome [SIRS] to infection) was the second cause of inclusion of patients. However, the source and/or the microbiological proof of infection have seldom been reported. This is very intriguing after almost 2 decades of striving - and with, sometimes, rigorous research - to establish the utility of a biomarker in less rigorous conditions. It is also, in our view, the biggest difficulty to overcome, since modern intensive care is becoming, alas, more and more syndromic. Of interest, the recently published and prematurely stopped study of Annane et al. [42] failed to include patients because $80.6 \%$ of the eligible patients had a documented source of infection within $48 \mathrm{~h}$ of recognition of SIRS (before randomization), $77.6 \%$ of whom had a documented pathogen. Now this was considered to be a major design flaw, but one definitely has to put into perspective the utility of a biomarker when modern pathogen identification techniques and experienced clinical judgment are combined. This point is very interestingly raised by Póvoa et al. [43], who reminded us of two studies, going 10 years back, that had shown the effectiveness of a shorter (6- 8 days) duration of antibiotic therapy to be equal to that of a long-term course (10-21 days) in VAP, but without the use of any biomarker. Hence, the decision to recommend PCT's usage in the recent guidelines for deescalation in lower RTIs even in the case of septic shock [44] leaves us skeptical. Proposals and recommendations for the use of PCT in a strategy aiming at antibiotic stewardship were issued by Schuetz et al. [41••] and Foushee et al. in 2012 [12••], each in distinct environments (Europe vs. Northern America, primary setting vs. low-, intermediate-, and high-risk patients), recommending caution regarding their implementation in immunocompromised and unstable patients. This is in line with most studies focusing on the need for supplementary data in favor of safe antibiotic stewardship, always encompassing PCT in a multimodal approach. A prospective upcoming and well-enrolled study (the SAPS study), the largest to be conducted so far in ICU patients, will perhaps be able to answer questions about the cost, safety, and effectiveness of such a strategy [45].

However, although convincing from the physiopathological and, sometimes, evidence-based point of view, PCT's systematical implementation as a prognostic tool or, for therapeutic monitoring, as a clinical algorithm for ICU patients has not been widely encouraged so far.

\section{Conclusion}

PCT as an antibiotic stewardship tool aiming at appropriately initiating antibiotics - that is, only in the setting of severe infection - has recently once again proven to be futile, if not detrimental. The 2013 surviving sepsis campaign (SSC) guidelines propose PCT as a diagnostic aid, in conjunction with the usual clinical signs, provided its value is superior to 2 standard deviations above the normal value. This is, in our opinion, a surrogate marker for poor sensitivity, and it would have been more prudent not to include it at all in the diagnostic strategy. Now, interest in PCT's ability to contribute to infected critically ill patients' diagnosis and prognosis has not worn out, as large-scale ongoing clinical studies attest (accessed on clinicaltrials.gov on May 13, 2013), but we are doubtful about their ultimate daily clinical implementation, given the amount of literature already available and the understandable reluctance of the intensive care physician, facing the possibility of uncontrolled sepsis, not to initiate antibiotics.

Hence, PCT as a therapeutic monitoring tool has looked like an attractive alternative in view of its high negative predictive value, but conclusive data concerning safety of this strategy are still lacking, at least in extra-thoracic severe sepsis. Concerning VAP, past studies have shown efficacious and safe shorter duration of antibiotic therapy without the need for a biomarker. Low adherence to protocol, even in the setting of controlled infection, is another hurdle to its implementation in daily clinical practice, since reports of overruling range from $16 \%$ to $65 \%[32 \cdot, 43]$. Only a grade $2 \mathrm{C}$ level of recommendation was attributed to PCT in the recently updated SSC guidelines when deescalation was considered. Rather, narrowing of the spectrum of antibiotics or stopping is left to "clinical judgment and information."

On the other hand, high-throughput molecular techniques such as multiplexed PCR and mass spectrometry allow more rapid and less empiric pathogen identification nowadays [46]. These techniques should be evaluated in terms of cost effectiveness, sensitivity, and specificity as part of a multimodal stewardship program in the ICU that could encompass bioscores such as the one recently described by Gibot et al. [47•]. This approach would thus imply a patient-tailored treatment based on individual phenotypic characteristics, combined with a biomarker allowing prompt stopping of antibiotics in the absence of infection or, even better, consensus on the optimal duration of therapy in sepsis without bacterial documentation.

\section{Compliance with Ethics Guidelines}

Conflict of Interest Nathalie Layios and Bernard Lambermont declare that they have no conflict of interest.

Human and Animal Rights and Informed Consent This article does not contain any studies with human or animal subjects performed by any of the authors. 


\section{References}

Papers of particular interest, published recently, have been highlighted as:

- Of importance

•- Of major importance

1. Assicot M, Gendrel D, Carsin H, et al. High serum procalcitonin concentrations in patients with sepsis and infection. Lancet. 1993;341:515-8.

2. Carvalhaes CG, Cayô R, Gales AC. Klebsiella pneumoniae Carbapenemase-Producing Klebsiella Pneumoniae in the Intensive Care Unit: A Real Challenge to Physicians, Scientific Community, and Society. Shock. 2013;39 Suppl 1:32-7.

3. Giuffrè M, Cipolla D, Bonura C, et al. Outbreak of colonizations by extended-spectrum $\beta$-lactamase-producing Escherichia coli sequence type 131 in a neonatal intensive care unit, Italy. Antimicrob Resist Infect Control. 2013;2:8

4. - Hausfater P, Garric S, Ayed SB, et al. Usefulness of procalcitonin as a marker of systemic infection in emergency department patients: a prospective study. Clin Infect Dis. 2002;34:895-901. Procalcitonin as a diagnostic tool in sepsis.

5. d'Escrivan T, Kipnis E, Robriquet L. Assessment of procalcitonin levels in emergency department patients. Clin Infect Dis. 2002;35:1275-6. author reply 1276 .

6. Ugarte H, Silva E, Mercan D, et al. Procalcitonin used as a marker of infection in the intensive care unit. Crit Care Med. 1999;27:498-504.

7. Vincent JL. Procalcitonin: THE marker of sepsis? Crit Care Med. 2000;28:1226-8.

8. Chan YL, Tseng CP, Tsay PK, et al. Procalcitonin as a marker of bacterial infection in the emergency department: an observational study. Crit Care. 2004;8:R12-20.

9. - Jensen JU, Heslet L, Jensen TH, et al. Procalcitonin increase in early identification of critically ill patients at high risk of mortality. Crit Care Med. 2006;34:2596-602. Procalcitonin as a prognostic tool.

10. - Jensen JU, Hein L, Lundgren B, et al. Procalcitonin-guided interventions against infections to increase early appropriate antibiotics and improve survival in the intensive care unit: a randomized trial. Crit Care Med. 2011;39:2048-58. Largest, negative, ICU trial.

11. Layios N, Damas P. The authors reply. Crit Care Med. 2013;41:e28.

12. •• Foushee JA, Hope NH, Grace EE. Applying biomarkers to clinical practice: a guide for utilizing procalcitonin assays. J Antimicrob Chemother. 2012;67:2560-9. Good review of procalcitonin physiopathology and clinical findings.

13. Brodska H, Drabek T, Malickova K, et al. Marked increase of procalcitonin after the administration of anti-thymocyte globulin in patients before hematopoietic stem cell transplantation does not indicate sepsis: a prospective study. Crit Care. 2009;13:R37.

14. Christ-Crain M, Morgenthaler NG, Stolz D, et al. Proadrenomedullin to predict severity and outcome in communityacquired pneumonia. Crit Care. 2006;10(3):R96.

15. Stolz D, Christ-Crain M, Bingisser R, et al. Antibiotic treatment of exacerbations of COPD: a randomized, controlled trial comparing procalcitonin-guidance with standard therapy. Chest. 2007;131:9-19.

16. Kofoed K, Andersen O, Kronborg G, et al. Use of plasma C-reactive protein, procalcitonin, neutrophils, macrophage migration inhibitory factor, soluble urokinase-type plasminogen activator receptor, and soluble triggering receptor expressed on myeloid cells- 1 in combination to diagnose infections: a prospective study. Crit Care. 2007;11: R38.

17. Huang DT, Weissfeld LA, Kellum JA, et al. Risk prediction with procalcitonin and clinical rules in community-acquired pneumonia. Ann Emerg Med. 2008;52:48-58. e2.
18. Viallon A, Guyomarc'h S, Marjollet O, et al. Can emergency physicians identify a high mortality subgroup of patients with sepsis: role of procalcitonin. Eur J Emerg Med. 2008;15:26-33.

19. Müller F, Christ-Crain M, Bregenzer T, et al. Procalcitonin levels predict bacteremia in patients with community-acquired pneumonia: a prospective cohort trial. Chest. 2010;138:121-9.

20. Carrol ED, Thomson AP, Hart CA. Procalcitonin as a marker of sepsis. Int J Antimicrob Agents. 2002;20:1-9.

21. Bloos F, Marshall JC, Dellinger RP, et al. Multinational, observational study of procalcitonin in ICU patients with pneumonia requiring mechanical ventilation: a multicenter observational study. Crit Care. 2011;15:R88.

22. Hausfater P, Juillien G, Madonna-Py B, et al. Serum procalcitonin measurement as diagnostic and prognostic marker in febrile adult patients presenting to the emergency department. Crit Care. 2007;11(3):R60.

23. Christ-Crain M, Jaccard-Stolz D, Bingisser R, et al. Effect of procalcitonin-guided treatment on antibiotic use and outcome in lower respiratory tract infections: cluster-randomised, singleblinded intervention trial. Lancet. 2004;363:600-7.

24. Simon L, Gauvin F, Amre DK, et al. Serum procalcitonin and Creactive protein levels as markers of bacterial infection: a systematic review and meta-analysis. Clin Infect Dis. 2004;39:206-17.

25. •• Nobre V, Harbarth S, Graf JD, et al. Use of procalcitonin to shorten antibiotic treatment duration in septic patients: a randomized trial. Am J Respir Crit Care Med. 2008;177:498-505. First ICU RCT evaluating de-escalation.

26. Gleckman RA, Czachor JS. Antibiotic side effects. Semin Respir Crit Care Med. 2000;21:53-60.

27. Granowitz EV, Brown RB. Antibiotic adverse reactions and drug interactions. Crit Care Clin. 2008;24:421-42.

28. Becker KL, Nylén ES, White JC, et al. Clinical review 167: Procalcitonin and the calcitonin gene family of peptides in inflammation, infection, and sepsis: a journey from calcitonin back to its precursors. J Clin Endocrinol Metab. 2004;89:1512-25.

29. Gilbert DN. Use of plasma procalcitonin levels as an adjunct to clinical microbiology. J Clin Microbiol. 2010;48:2325-9.

30. Layios N, Lambermont B, Canivet JL, et al. Procalcitonin usefulness for the initiation of antibiotic treatment in intensive care unit patients. Crit Care Med. 2012;40:2304-9.

31. Menéndez R, Sahuqillo-Arcoe JM, Reyes S, et al. Cytokine activation patterns and biomarkers Are influenced by microorganisms in community-acquired pneumonia. Chest. 2012;141(6):1537-45.

32. - Heyland DK, Johnson AP, Reynolds SC, et al. Procalcitonin for reduced antibiotic exposure in the critical care setting: a systematic review and an economic evaluation. Crit Care Med. 2011;39:1792-9. Cost-effectiveness positive trial.

33. Bouadma L, Luyt CE, Tubach F, et al. Use of procalcitonin to reduce patients' exposure to antibiotics in intensive care units (PRORATA trial): a multicentre randomised controlled trial. Lancet. 2010;375:463-74.

34. Stolz D, Smyrnios N, Eggimann P, et al. Procalcitonin for reduced antibiotic exposure in ventilator-associated pneumonia: a randomised study. Eur Respir J. 2009;34:1364-75.

35. Brunkhorst FM, Heinz U, Forycki ZF. Kinetics of procalcitonin in iatrogenic sepsis. Intensive Care Med. 1998;24:888-9.

36. Christ-Crain M, Opal SM. Clinical review: the role of biomarkers in the diagnosis and management of community-acquired pneumonia. Crit Care. 2010;14:203.

37. Johansen ME, Jensen JU, Lundgren JD. Antibiotics in intensive care: too little or too much? Crit Care Med. 2011;39:1849-51.

38. Hayashi Y, Paterson DL. Strategies for reduction in duration of antibiotic use in hospitalized patients. Clin Infect Dis. 2011;52:1232-40.

39. • Matthaiou DK, Ntani G, Kontogiorgi M, et al. An ESICM systematic review and meta-analysis of procalcitonin-guided antibiotic 
therapy algorithms in adult critically ill patients. Intensive Care Med. 2012;38:940-9. ESICM (positive) meta-analysis.

40. Schuetz P, Briel M, Christ-Crain M, et al. Procalcitonin to guide initiation and duration of antibiotic treatment in acute respiratory infections: an individual patient data meta-analysis. Clin Infect Dis. 2012;55:651-62.

41. •• Schuetz P, Chiappa V, Briel M, et al. Procalcitonin algorithms for antibiotic therapy decisions: a systematic review of randomized controlled trials and recommendations for clinical algorithms. Arch Intern Med. 2011;171:1322-31. Positive review of randomized controlled trials investigating procalcitonin to desescalade antibiotics in primary and acute care settings.

42. Annane D, Maxime V, Faller JP, et al. Procalcitonin levels to guide antibiotic therapy in adults with non-microbiologically proven apparent severe sepsis: a randomised controlled trial. BMJ Open. 2013;3(2).

43. Póvoa P, Salluh JI. Biomarker-guided antibiotic therapy in adult critically ill patients: a critical review. Ann Intensive Care. 2012;2:32.

44. Woodhead M, Blasi F, Ewig S, et al. Guidelines for the management of adult lower respiratory tract infections-full version. Clin Microbiol Infect. 2011;17 Suppl 6:E1-59.

45. Assink-de Jong E, de Lange DW, van Oers JA, et al. Stop Antibiotics on guidance of Procalcitonin Study (SAPS): a randomised prospective multicenter investigator-initiated trial to analyse whether daily measurements of procalcitonin versus a standard-of-care approach can safely shorten antibiotic duration in intensive care unit patients - calculated sample size: 1816 patients. BMC Infect Dis. 2013;13:178.

46. Murray PR, Masur H. Current approaches to the diagnosis of bacterial and fungal bloodstream infections in the intensive care unit. Crit Care Med. 2012;40:3277-82.

47. - Gibot S, Béné MC, Noel R, et al. Combination biomarkers to diagnose sepsis in the critically ill patient. Am J Respir Crit Care Med. 2012;186:65-71. First bioscore to include individual phenotypic data and PCT.

48. Schroeder S, Hochreiter M, Koehler T, et al. Procalcitonin (PCT)guided algorithm reduces length of antibiotic treatment in surgical intensive care patients with severe sepsis: results of a prospective randomized study. Langenbecks Arch Surg. 2009;394(2):221-6.

49. Hochreiter M, Köhler T, Schweiger AM, et al. Procalcitonin to guide duration of antibiotic therapy in intensive care patients: a randomized prospective controlled trial. Crit Care. 2009;13(3):R83.

50. Argawal R, Schwartz D. Procalcitonin to guide duration of antimicrobial therapy in Intensive Care Units. Clin Infect Dis. 2011;53:379-87.

51. Hohn A, Schroeder S, Gehrt A, et al. Procalcitonin-guided algorithm to reduce length of antibiotic therapy in patients with severe sepsis and septic shock. BMC Infect Dis. 2013;13:158. 